\title{
Schrödinger's cat extinction paradox
}

\author{
David L. Roberts and Martin Fisher
}

Not unexpectedly the pages of this journal have often touched on the subject of extinction-from the Latin exstinguere, to quench-whether the risk of extinction or an investigation of whether a taxon is extinct. This issue of Oryx revisits this theme, examining cases of species that are either extinct or threatened with extinction to varying degrees. At one extreme lies the Catarina pupfish Megupsilon aporus, the only representative of its genus and once endemic to a single freshwater spring in Mexico. The species was known to science for a mere 22 years before it became extinct in the wild, in 1994, following predation by the introduced largemouth bass Micropterus salmoides and, ultimately, the drying out of the spring as a result of overextraction of water for agriculture. The species persisted in captivity for a further 10 years but ex situ breeding was unsuccessful and the last few captive individuals died in 2004 (Valdés González et al., 2020). Given the absence of doubt, it is categorized as Extinct on the IUCN Red List. Less extreme, but still precarious, are the cases of the Critically Endangered ploughshare tortoise Astrochelys yniphora of Madagascar, pressurized by hunting for the international illegal pet trade (Mandimbihasina et al., 2020), and the poorly known but Endangered Annamite striped rabbit of Viet Nam and Lao, threatened by hunting for consumption, and one of many species caught in the South-east Asian extinction crisis (Tilker et al., 2020a,b). These examples clearly illustrate the impact we are having on other species, and that our activities are not just leading to declines but also directly to extinctions.

For some species, lack of knowledge can lead to threats going unnoticed. One such case is Gurney's pitta, a ground dwelling bird from Myanmar and Thailand. In 2017 it was categorized as Endangered, but new knowledge has dramatically altered this assessment: it is now categorized as Critically Endangered, possibly on the brink of extinction (Shwe et al., 2020). However, Gurney's pitta has at least been assessed, even though it is now recognized to be more threatened than formerly believed. Of the c. 1.8 million named species, most have never been the subject of any assessment of extinction risk: the number of species requiring attention is daunting (Fisher, 2019). In this issue of Oryx,

DAVID L. ROBERTS (10) orcid.org/0000-0001-6788-2691) Durrell Institute of Conservation and Ecology, School of Anthropology and Conservation, Marlowe Building, University of Kent, Canterbury, Kent, CT2 7NR, UK E-mail d.l.roberts@kent.ac.uk

MARTIN Fisher (10) orcid.org/0000-0001-5044-2585) Fauna \& Flora International, Cambridge, UK however, the Mediterranean rock rose Helianthemum caput-felis is assessed for the first time, and found to be Endangered (Sulis et al., 2020). There are additional, vexing problems regarding the extinction of non-charismatic species. An extreme example is the co-extinction of parasites along with their hosts, and the possibility that some parasite species have gone extinct as a result of conservation efforts (Rózsa \& Vas, 2015).

Although our understanding of extinction risk is changing species by species, at its most basic a species' status at a particular point in time is a binary argument, it either exists or it does not. If the species does exist, then this can lead to a second binary argument, that is whether the species is threatened with extinction (Vulnerable, Endangered or Critically Endangered) or not (Near Threatened or Least Concern). Knowing whether a species is extinct or extant is fundamental for effective conservation decision-making, including the assignment of a threatened status. Errors in categorizing the status of a species can have dramatic consequences, such as the Romeo Error (Collar, 1998). This refers to cases where a species is presumed extinct when in fact it is extant, but by presuming it is extinct no conservation action is taken, leading to the species' extinction. Errors may arise in part because of the uncertainty as to which side of the argument the species falls. Some species may thus enter a state of limbo akin to that of Schrödinger's cat, paradoxically thought of as both dead and alive-the Red List interpretation of which is the category Critically Endangered (Possibly Extinct). This problem arises because it is easy to prove that a species is present, if you have the evidence, but proving a species is not present is more challenging. As a species approaches extinction it becomes increasingly rare and therefore the evidence of its persistence becomes fragmented and often questionable. This issue of data paucity is not restricted to species approaching extinction. It actually affects the majority of species as most are naturally rare: it is rare to be common, but common to be rare. This is illustrated by Roberts \& Jaric (2020) in their attempt to determine the extinction status of 236 species of Malagasy orchids, each known only from a single collection. For a species that is extinct, this data paucity is unlikely to change significantly as ultimately there is a finite amount of data that can be accumulated. All that is left of a species is remanence of its former existence.

Although time since last sighting is a familiar currency of extinction declarations-which are often informal-it is not the only attribute of a species that should be relied upon. The definition of the Red List category Extinct mentions 
other attributes such as 'exhaustive surveys' at 'appropriate times' that are 'appropriate to the taxon's life cycle and life form' (IUCN, 2012). In response, the IUCN Red List (IUCN Standards and Petitions Committee, 2019) and others (Silcock et al., 2020) have developed frameworks for declaring a species extinct or extant, but as time since last sighting is easy to measure and a familiar attribute of a species it is still frequently relied upon in declarations of extinction.

Extinction is an emotive, saddening subject. Because of this the word is often used to garner support for conservation action in narratives of species rediscoveries, to enhance a feeling of excitement, even of optimism. However, it is the lack of sightings over a long period of time that gives rise to the notion of a perceived novel sighting being a rediscovery, often leading to retrospective assertions of formerly presumed extinction. In many cases the rediscovered species was never formally considered extinct and at most this may have been mooted informally. Even when a species has been rediscovered and extinction has been incorporated into the rediscovery narrative, there is often little attempt to determine whether a declaration of extinction would have been justified prior to its rediscovery.

We are in a time of immense environmental upheaval, with more species transitioning from being extant to being extinct. Against this backdrop there remain nevertheless glimmers of hope (Balmford, 2017; Knowlton, 2019). One such case being the rediscovery of the plant Dracaena umbraculifera (Edwards et al., 2018) of Madagascar, which was formerly presumed extinct. Another case comes from the gloom of the mass extirpation of the partulid snails of the Society Islands: two species of Partula survived, perhaps because, although rare, they are fecund (Lee et al., 2008). Thus we need to remember that the word extinct has profound meaning and implications. We need to move beyond using extinct as a sound bite and treat it with the gravity it deserves, and to remember that, because of the very nature of extinction, assessing a species as Extinct is littered with uncertainties. As many of the rarest species enter Schrödinger's cat extinction paradox, being considered simultaneously extinct and extant, we need to continue improving methodologies for both inferring extinction and extinction risk.

This Editorial and the Oryx articles cited herein are freely available as a virtual issue of the journal at cambridge.org/ core/journals/oryx/virtual-issues.

\section{References}

Balmford, A. (2017) On positive shifting baselines and the importance of optimism. Oryx, 51, 191-192.

Collar, N.J. (1998) Extinction by assumption: or, the Romeo Error on Cebu. Oryx, 32, 239-244.

Edwards, C.E., Bassúner, B., Birkinshaw, C., Camara, C., Lehavana, A., Lowry, P.P., et al. (2018) A botanical mystery solved by phylogenetic analysis of botanical garden collections: the rediscovery of the presumed-extinct Dracaena umbraculifera. Oryx, 52, 427-436.

Fisher, M. (2019) The small, the hidden, the less-loved: conserving other species. Oryx, 53, 199-200.

IUCN (2012) IUCN Red List Categories and Criteria: Version 3.1. 2nd edition. Gland, Switzerland, and Cambridge, UK. portals.iucn.org/ library/node/10315 [accessed 20 December 2019].

IUCN Standards and Petitions Committee (2019) Guidelines for Using the IUCN Red List Categories and Criteria. Version 14. Prepared by the Standards and Petitions Committee. iucnredlist.org/ documents/RedListGuidelines.pdf [accessed 20 December 2019].

Knowlton, N. (2019) Earth Optimism-recapturing the positive. Oryx , 53, 1-2.

Lee, T., Meyer, J.-Y., Burch, J.B., Pearce-Kelly, P. \& Ó Foighil, D. (2008) Not completely lost: two partulid tree snail species persist on the highest peak of Raiatea, French Polynesia. Oryx, 42, $615-619$.

Mandimbihasina, A.R., Woolaver, L.G., Concannon, L.E., Milner-Gulland, E.J., Lewis, R.E., Terry, A.M.R. et al. (2020) The illegal pet trade is driving Madagascar's ploughshare tortoise to extinction. Oryx, 54, 188-196.

Roberts, D.L. \& JARIĆ., I. (2020) Inferring the extinction of species known only from a single specimen. Oryx, 54, 161-166.

RózsA, L. \& VAs, Z. (2015) Co-extinct and critically co-endangered species of parasitic lice, and conservation-induced extinction: should lice be reintroduced to their hosts? Oryx, 49, 107-110.

Shwe, N.M., Sukumal, N., Grindley, M. \& Savini, T. (2020) Is Gurney's pitta Hydrornis gurneyi on the brink of extinction? Oryx, 54, 16-22.

Silcock, J.L., Field, A.R., Walsh, N.G. \& Fensham, R.J. (2020) To name those lost: assessing extinction likelihood in the Australian vascular flora. Oryx, 54, 167-177.

Sulis, E., Bacchetta, G., Cogoni, D., Gargano, D. \& Fenu, G. (2020) Assessing the global conservation status of the rock rose Helianthemum caput-felis. Oryx, 54, 197-205.

Tilker, A., Nguyen, A., Abrams, J.F., Bhaghat, T., Le, M., NGUYen, T.V. et al. (2020a) A little-known endemic caught in the South-east Asian extinction crisis: the Annamite striped rabbit Nesolagus timminsi. Oryx, 54, 178-187.

Tilker, A., Nguyen, A., Timmins, R.J., Gray, T.N.E., Steinmetz, R., Abramov, A.V. \& Wilkinson, N. (2020b) No longer Data Deficient: recategorizing the Annamite striped rabbit Nesolagus timminsi as Endangered. Oryx, 54, 151.

Valdés González, A., Martínez Estévez, L., Ángeles Villeda, M.E. \& Ceballos, G. (2020) The extinction of the Catarina pupfish Megupsilon aporus and the implications for the conservation of freshwater fish in Mexico. Oryx, 54, 154-160. 